\title{
A Comparative Study of Weight Loss and Reduction in BMI after Gastric Imbrication, Sleeve Gastrectomy, and Roux-en-Y Gastric Bypass
}

\author{
Pankaj Tejasvi ${ }^{1}$, Arvind Ghanghoria ${ }^{2}$, Ruchita Banseria ${ }^{3}$
}

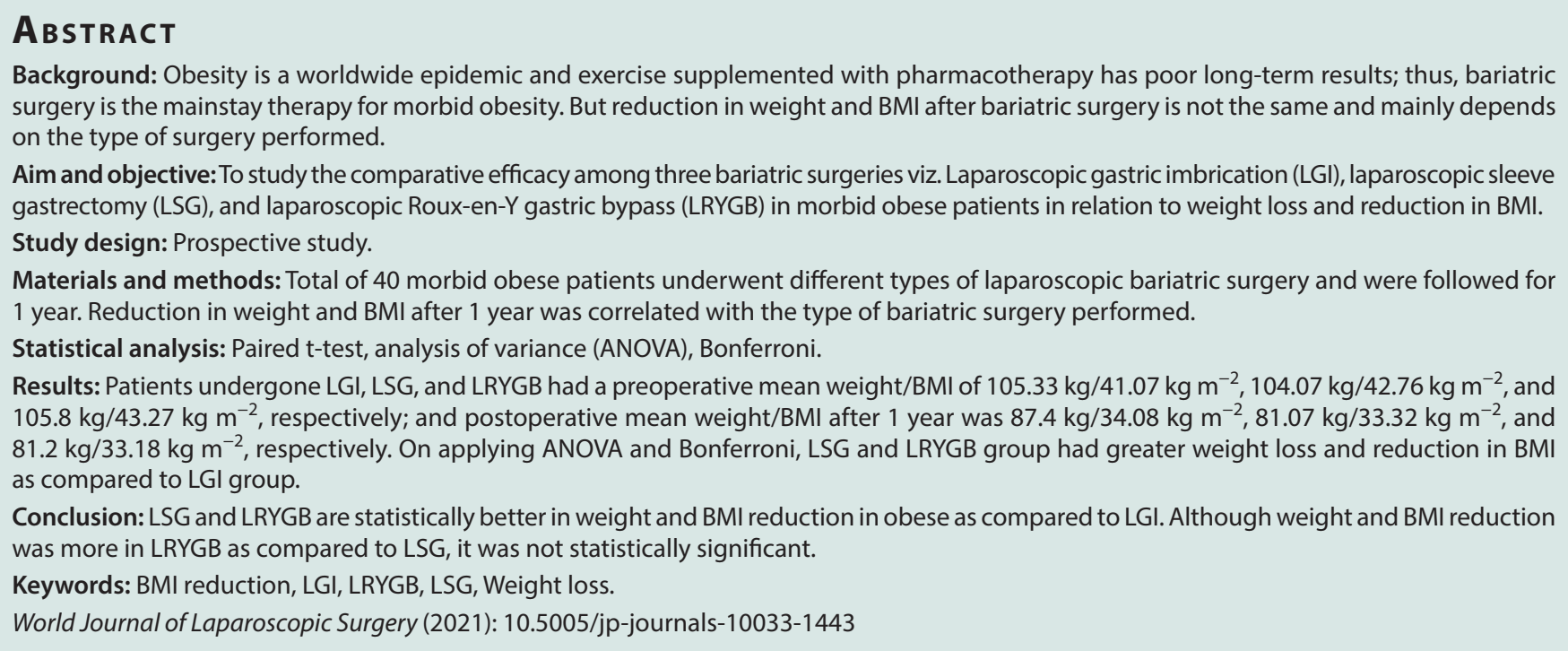

\section{INTRODUCTION}

Obesity is a medical condition in which excess body fat has accumulated to the extent that it may have a negative effect on health. ${ }^{1}$ The main cause of obesity and overweight is an energy imbalance between calories consumed and calories expended.

A dietary therapy with exercise supplemented with pharmacotherapy, generally achieved only minimal and often transient effects with poor long-term results; however, the National Institutes of Health (NIH) Consensus Development Panel recommended that patients seeking therapy for severe obesity for the first time should be considered for treatment in a nonsurgical program that integrates a dietary regimen, appropriate exercise, behavior modification, and psychological support. ${ }^{2}$ With long-term follow-up, bariatric surgeries sustainably decreased weight, HbA1c, and fasting blood sugar (FBS). ${ }^{3}$

But in spite of strict patient selection, the reduction in weight and BMI after bariatric surgery is not the same. Through this study, we wished to look for any significant correlation between the type of bariatric surgery and reduction in weight and BMI.

\section{Aims and Objectives}

To study the comparative efficacy among three bariatric surgeries viz. laparoscopic gastric imbrication (LGI), laparoscopic sleeve gastrectomy (LSG), and laparoscopic Roux-en-Y gastric bypass
${ }^{1}$ Department of Urology, Andhra Medical College, Visakhapatnam, Andhra Pradesh, India

${ }^{2}$ Department of General Surgery, Mahatama Gandhi Memorial Medical College, Indore, Madhya Pradesh, India

${ }^{3}$ Department of Preventive and Social Medicine, Mahatama Gandhi Memorial Medical College, Indore, Madhya Pradesh, India

Corresponding Author: Pankaj Tejasvi, Department of Urology, Andhra Medical College, Visakhapatnam, Andhra Pradesh, India, Phone: +918818800175, e-mail: pankajtejasvi@hotmail.com

How to cite this article: Tejasvi P, Ghanghoria A, Banseria R. A Comparative Study of Weight Loss and Reduction in BMI after Gastric Imbrication, Sleeve Gastrectomy, and Roux-en-Y Gastric Bypass. World J Lung Surg 2021;14(1):26-29.

Source of support: Nil

Conflict of interest: None

(LRYGB) in morbid obese patients in relation to weight loss and reduction in BMI.

\section{Materials and Methods}

A prospective study was conducted at MGMMC and Maharaja Yashwantrao Hospital, Indore in the Department of Surgery. A total of 40 morbid obese patients aged between 19 years to 50 years and

() Jaypee Brothers Medical Publishers. 2021 Open Access This article is distributed under the terms of the Creative Commons Attribution 4.0 International License (https://creativecommons.org/licenses/by-nc/4.0/), which permits unrestricted use, distribution, and non-commercial reproduction in any medium, provided you give appropriate credit to the original author(s) and the source, provide a link to the Creative Commons license, and indicate if changes were made. The Creative Commons Public Domain Dedication waiver (http://creativecommons.org/publicdomain/zero/1.0/) applies to the data made available in this article, unless otherwise stated. 
BMI $\geq 40 \mathrm{~kg} / \mathrm{m}^{2}$ or BMI $>35 \mathrm{~kg} / \mathrm{m}^{2}$ with obesity-related comorbid conditions like diabetes mellitus, hypertension, and dyslipidemia were included in the study from July 2014 to April 2016. The same team of surgeons was involved in all the cases.

All patients fulfilled the NIH criteria ${ }^{4}$ and were thoroughly evaluated preoperatively, and the type of bariatric surgery was explained to the patients and was selected by them, with written informed consent for the same. Patients were followed up at 2 weeks, 1 month, 6 months, and 1 year postoperatively. Weight, $\mathrm{BMI}$, excess weight loss, random blood sugar, systolic and diastolic blood pressure, and any complication following surgery were documented at each visit.

\section{Statistical Analysis}

Paired t-test (two-tailed, dependent) has been used to find the significance of study parameters on a continuous scale within each group. Bonferroni and analysis of variance (ANOVA) have been used to find the significance of study parameters between different groups. For the analysis of the data, statistical software IBM SPSS Statistics version 20.0 was used.

$P$-value of less than 0.05 was considered statistically significant.

\section{Results}

Forty morbid obese patients were included in the study, of which 29 were females and 11 were males. Age varied from 19 to 50 years with a mean of 37.75 years. Patients undergone LGI, LSG, and LRYGB had a preoperative mean weight of $105.33 \pm 8.87 \mathrm{~kg}, 104.07 \pm 9.55 \mathrm{~kg}$, and $105.8 \pm 9.52 \mathrm{~kg}$, respectively; and a preoperative mean BMI of $41.07 \pm 2.51 \mathrm{~kg} \mathrm{~m}^{-2}, 42.76 \pm 3.81 \mathrm{~kg} \mathrm{~m}^{-2}$, and $43.27 \pm 3.59 \mathrm{~kg} \mathrm{~m}^{-2}$, respectively (Fig. 1).

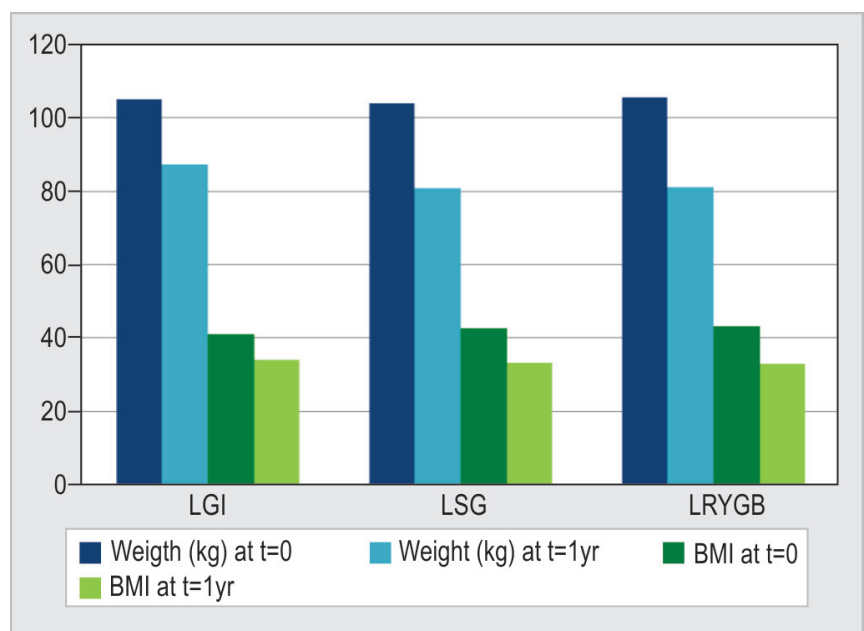

Fig. 1: Graph showing preoperative and postoperative weight and BMI
Postoperative mean weight after 1 year was $87.4 \pm 6.58 \mathrm{~kg}$, $81.07 \pm 6.32 \mathrm{~kg}$, and $81.2 \pm 7.04 \mathrm{~kg}$ in patients undergone LGI, LSG, and LRYGB, respectively; and Postoperative mean BMI after 1 year was $34.08 \pm 1.56 \mathrm{~kg} \mathrm{~m}^{-2}, 33.32 \pm 2.65 \mathrm{~kg} \mathrm{~m}^{-2}$, and $33.18 \pm 2.24 \mathrm{~kg} \mathrm{~m}^{-2}$, respectively (Fig. 1 and Table 1).

On comparison of preoperative weight and BMI to the corresponding variable 1 year after surgery, the weight loss and reduction in BMI were statistically significant in all the surgery groups.

On comparison of reduction in weight and BMI after 1 year of surgery between the different surgical groups, it was found that reduction in these parameters was more in LRYGB and LSG than in LGI, and the difference is statistically significant (Tables 2 and 3). Although the reduction in weight and BMI after 1 year of surgery was more in LRYGB than in LSG, the difference was not statistically significant (Table 3).

\section{Discussion}

The worldwide prevalence of obesity more than doubled between 1980 and $2014 .{ }^{5}$ WHO estimated that in 2014, more than 1.9 billion adults aged 18 years and older were overweight. Of these over 600 million adults were obese. Overall, about $13 \%$ of the world's adult population ( $11 \%$ of men and $15 \%$ of women) were obese and $39 \%$ (38\% of men and $40 \%$ of women) were overweight in $2014 .^{5}$

Dietary therapy with exercise supplemented with pharmacotherapy, with or without organization supervision, generally achieved only minimal and often transient effects with poor long-term results. Once severely obese, the likelihood that a person will lose enough weight by dietary means alone and remain at a BMI below $35 \mathrm{~kg} / \mathrm{m}^{2}$ is estimated at $3 \%$ or less. The $\mathrm{NIH}$ consensus conference recognized that for this patient population, nonsurgical therapy has been uniformly unsuccessful in treating the problem. ${ }^{4}$

The rise in the prevalence of obesity led to increase interest in the surgical approach to treat obesity, and in 1991, the NIH established guidelines for surgical therapy of morbid obesity now known as bariatric surgery. ${ }^{2}$

A range of different bariatric procedures are available, working on principles of restriction or malabsorption or both. Along with reducing weight, some of them have been shown to reduce appetite and improve glucose homeostasis independently of weight loss. In view of its favorable metabolic effects, bariatric surgery is also referred to as "metabolic surgery."

Sleeve gastrectomy was initially described in 1988 by Hess ${ }^{6}$ and Marceau ${ }^{7}$ during the duodenal switch and 1993 by Johnston ${ }^{8}$ in an isolated form.

The gastric imbrication procedure involves plicating the greater curvature of the stomach after the division of the short gastric vessels. It is a relatively new technique. It was initially proposed by Wilkinson and Paleso 9,10 and introduced in 2006 by Dr. Talebpour in

Table 1: Analysis of weight and BMI reduction 1 year after surgery within a surgical group

\begin{tabular}{|c|c|c|c|c|c|c|}
\hline & \multicolumn{2}{|l|}{$L G I$} & \multicolumn{2}{|l|}{$L S G$} & \multicolumn{2}{|l|}{$L R Y G B$} \\
\hline & Weight (kg) & $\mathrm{BMI}\left(\mathrm{kg} \mathrm{m}^{-2}\right)$ & Weight (kg) & $\mathrm{BMI}\left(\mathrm{kg} \mathrm{m}^{-2}\right)$ & Weight (kg) & BMI $\left(\mathrm{kg} \mathrm{m}^{-2}\right)$ \\
\hline Preoperative; $t=0$ & $105.33 \pm 8.87$ & $41.07 \pm 2.51$ & $104.07 \pm 9.55$ & $42.76 \pm 3.81$ & $105.8 \pm 9.52$ & $43.27 \pm 3.59$ \\
\hline Postoperative; $t=1$ year & $87.4 \pm 6.58$ & $34.08 \pm 1.56$ & $81.07 \pm 6.32$ & $33.32 \pm 2.65$ & $81.2 \pm 7.04$ & $33.18 \pm 2.24$ \\
\hline $\begin{array}{l}\text { (Paired t-test) } \\
P \text {-value }\end{array}$ & 0.000 & 0.000 & 0.000 & 0.000 & 0.000 & 0.000 \\
\hline
\end{tabular}


Comparative Outcome of LGI, LSG and LRYGB for Weight Loss and BMI Reduction

Table 2: Analysis of weight and BMI reduction 1 year after surgery between different surgical groups

\begin{tabular}{|c|c|c|c|c|c|c|c|}
\hline & \multicolumn{2}{|c|}{$L G I$} & \multicolumn{2}{|c|}{ LSG } & \multicolumn{2}{|c|}{$L R Y G B$} & \multirow{2}{*}{$\begin{array}{l}\text { (ANOVA) } \\
\text { P-value }\end{array}$} \\
\hline & $\begin{array}{l}\text { Preoperative; } \\
t=0\end{array}$ & $\begin{array}{l}\text { Postoperative; } \\
t=1 \text { year }\end{array}$ & $\begin{array}{l}\text { Preoperative; } \\
t=0\end{array}$ & $\begin{array}{l}\text { Postoperative; } \\
t=1 \text { year }\end{array}$ & $\begin{array}{l}\text { Preoperative; } \\
t=0\end{array}$ & $\begin{array}{l}\text { Postoperative; } \\
t=1 \text { year }\end{array}$ & \\
\hline Weight (kg) & $105.33 \pm 8.87$ & $87.4 \pm 6.58$ & $104.07 \pm 9.55$ & $81.07 \pm 6.32$ & $105.8 \pm 9.52$ & $81.2 \pm 7.04$ & 0.001 \\
\hline BMI $\left(\mathrm{kg} \mathrm{m}^{-2}\right)$ & $41.07 \pm 2.51$ & $34.08 \pm 1.56$ & $42.76 \pm 3.81$ & $33.32 \pm 2.65$ & $43.27 \pm 3.59$ & $33.18 \pm 2.24$ & 0.000 \\
\hline
\end{tabular}

Table 3: Comparison of weight and BMI reduction 1 year after different bariatric surgeries

\begin{tabular}{|c|c|c|c|c|}
\hline & $L G I$ & LSG & $L R Y G B$ & $\begin{array}{l}\text { (Bonferroni) } \\
\text { P-value }\end{array}$ \\
\hline Mean reduction in weight 1 year after surgery $(\mathrm{kg})$ & $17.93 \pm 3.49$ & $23.00 \pm 4.72$ & $24.60 \pm 5.39$ & \\
\hline $\begin{array}{l}\text { Comparing } \\
\cdot \text { LGI and LSG } \\
\cdot \text { LGI and LRYGB } \\
\cdot \text { LSG and LRYGB }\end{array}$ & & & & $\begin{array}{l}0.011 \\
0.002 \\
1.000\end{array}$ \\
\hline Mean reduction in BMI 1 year after surgery $\left(\mathrm{kg} \mathrm{m}^{-2}\right)$ & $6.99 \pm 1.33$ & $9.43 \pm 1.85$ & $10.08 \pm 2.41$ & \\
\hline $\begin{array}{l}\text { Comparing } \\
\cdot \text { LGI and LSG } \\
\cdot \text { LGI and LRYGB } \\
\cdot \text { LSG and LRYGB }\end{array}$ & & & & $\begin{array}{l}0.003 \\
0.001 \\
1.000\end{array}$ \\
\hline
\end{tabular}

Iran. ${ }^{11}$ Since here resection of the stomach has not been performed, the decrement in the ghrelin levels is unlikely as they do in sleeve gastrectomy. The gastric imbrication procedure has a technical advantage when compared to LSG; that is, there are no resection and anastomosis of the stomach lines and thus no risk of leak from the staple line. The procedure is reversible and cost-effective.

Gastric bypass was initially developed by Dr. Mason and Ito in the 1960s. ${ }^{12}$ Over several decades, the gastric bypass has been modified into its current form, using a RYGBP limb of the intestine. In 1994, Dr. Wittgrove and Clark reported the first case series of laparoscopic RYGBP. ${ }^{13}$

In our study, all the patients were preoperatively thoroughly evaluated for comorbidities and anesthetic risk. Preoperative ECG, lipid profile, thyroid function test, LFT, FBS, HbA1c, Hb level, hematocrit, platelet count, serum creatinine, and serum electrolyte were done. In women, Pap smears and pregnancy testing should be performed. Posteroanterior and lateral radiographs of the chest were also evaluated.

Fifteen morbid obese patients underwent LSG, in which greater curvature of the stomach was cut and stapled over a $34 \mathrm{Fr}$ bougie, starting from $6 \mathrm{~cm}$ proximal to pylorus toward the angle of His, using Endo GIA $^{\mathrm{TM}}$ stapler. In our study, the effective weight loss was $53.73 \%$ after 1 year, it was $66 \%$ after 36 months in a study conducted by Himpens et al., ${ }^{14}$ and $54 \%$ after 12 months reported by PP Cutolo et al. ${ }^{15}$

Fifteen morbid obese patients underwent LGI, in which greater curvature of the stomach was plicated over a $34 \mathrm{Fr}$ bougie, the first row of extramucosal continuous suture, and a second layer of interrupted suture. The effective weight loss was $43.53 \%$ after 1 year, it was $61 \%$ after 12 months in a study conducted by Talebpour and Amoli, $^{11}$ and $67.1 \%$ after 12 months according to 2011 Skrekas et al. ${ }^{16}$ publication.

Ten morbid obese patients underwent LRYGB, in which $30 \mathrm{ml}$ gastric pouch and $50 \mathrm{~cm}$ of Roux-limb were created. The effective weight loss was $55.37 \%$ after 1 year, it was $60.5 \%$ after 12 months in a study conducted by Karamanakos et al., ${ }^{17}$ and $62 \%$ after 36 months according to Kehagias et al. ${ }^{18}$
There were no intraoperative complications. Postoperative on the first day, nausea was reported by most of the patients, which resolved gradually by antiemetics. There were no other significant postoperative complications. Deep vein thrombosis (DVT) prophylaxis was given to all. Patients were discharged when their vitals were stable able to accept liquid diet and could tolerate pain. Postoperatively patients were advised to have liquid diet for 10 days, proton pump inhibitors for 3 months, and multivitamins. Follow-up visits were scheduled at 2 weeks, 1 month, 6 months, and 1 year postoperatively.

On comparing the three surgery groups, LSG and LRYGB were statistically better in weight and BMI reduction in obese as compared to LGI. Although weight and BMI reduction was more in LRYGB as compared to LSG, it was not statistically significant.

\section{References}

1. Obesity and overweight Fact sheet N³11. WHO. January 2015. Accessed 2 February 2016.

2. NIH conference. Gastrointestinal surgery of severe obesity. Consensus Development panel. Ann intern Med. 1991;115(12): 956-961. PMID: 1952493.

3. Bradley D, Magkos F, Klein S. Effects of bariatric surgery on glucose homeostasis and type 2 diabetes. Gastroenterology 2012;143(4):897912. DOI: 10.1053/j.gastro.2012.07.114.

4. Gastrointestinal surgery for severe obesity: National Institutes of Health Consensus Development Conference Statement. Am J Clin Nutr 1992 Feb; 55(2 Suppl):615S-619S. DOI: 10.1093/ajcn/55.2.615s.

5. WHO Obesity and overweight. Fact sheet. Updated June 2016.

6. Hess DS, Hess DW. Biliopancreatic diversion with a duodenal switch. Obes Surg 1998; 8(3):267-282. DOI: 10.1381/096089298765554476.

7. Marceau P, Hould FS, Simard S, et al. Biliopancreatic diversion with duodenal switch. World J Surg 1998;22(9):947-954. DOI: 10.1007/ s002689900498.

8. Johnston D, Dachtler J, Sue-Ling HM, et al. The Magenstrasse and mill operation for morbid obesity. Obes Surg 2003;13:10-16. DOI: 10.1381/096089203321136520.

9. Wilkinson LH. Reduction of gastric reservoir capacity. Am J Clin Nutr 1980;33(2 Suppl):515-517. DOI: 10.1093/ajcn/33.2.515.

10. WilkinsonLH,PelosoOA.Gastric(reservoir) reduction of morbidobesity. Arch Surg 1981;116(5):602-605. DOI: 10.1001/archsurg.1981.01380170082014. 
11. Talebpour M, Amoli BS. Laparoscopic total gastric vertical plication in morbid obesity. J Laparoendosc Adv Surg Tech 2007;17(6):793-798. DOI: 10.1089/lap.2006.0128.

12. Mason EE, Ito C. Gastric bypass in obesity. Surg Clin North Am 1967;47:1345-1351. DOI: 10.1016/s0039-6109(16)38384-0.

13. Wittgrove AC, Clark GW, Tremblay LJ. Laparoscopic gastric bypass, Roux- en-Y: preliminary report of five cases. Obes Surg 1994;4:353357. DOI: $10.1381 / 096089294765558331$.

14. Himpens J, Dapri G, Cadière GB. A prospective randomized study between laparoscopic gastric banding and laparoscopic isolated sleeve gastrectomy: results after 1 and 3 years. Obes Surg 2006;16(11):1450-1456. DOI: 10.1381/096089206778869933.

15. Cutolo PP, Vitolo G, Brancato V, et al. Clinical efficacy of laparoscopic sleeve gastrectomy vs laparoscopic gastric bypass in obese type 2 diabetic patients: a retrospective comparison. Obes Surg 2012;22(10):1535-1539

16. Skrekas G, Antiochos K, Stafyla VK. Laparoscopic gastric greater curvature plication: results and complications in a series of 135 patients. Obes Surg 2011;21(11):1657-1663. DOI: 10.1007/s11695-011-0499-6.

17. Karamanakos SN, Vagenas K, Kalfarentzos F, et al. Weight loss, appetite suppression, and changes in fasting and postprandial ghrelin and peptide-YY levels after Roux-en-Y gastric bypass and sleeve gastrectomy: a prospective, double blind study. Ann Surg 2008;247(3):401-407. DOI: 10.1097/SLA.0b013e318156f012.

18. Kehagias I, Karamanakos SN, Argentou M, etal. Randomized clinical trial of laparoscopic Roux-en-Y gastric bypass versus laparoscopic sleeve gastrectomy for the management of patients with $B M I<50 \mathrm{~kg} / \mathrm{m}^{2}$. Obes Surg 2011;21(11):1650-1656. DOI: 10.1007/s11695-011-0479-x. 